\title{
LA PROMOCIÓN HORIZONTAL EN EDUCACIÓN BÁSICA: UN DERECHO POLIÉDRICO Y UN TEMA PENDIENTE EN NAYARIT*
}

\author{
THE HORIZONTAL PROMOTION IN BASIC EDUCATION: \\ A POLYHEDRAL RIGHT AND A PENDING SUBJECT IN NAYARIT \\ LA PROMOTION HORIZONTALE DANS L'ÉDUCATION DE LA \\ MATERNELLE JUSQU'AU COLLÈGE: UN DROIT MULTIFACETTE \\ ET UNE QUESTION TOUJOURS D'ACTUALITÉ DANS L'ÉTAT \\ DE NAYARIT
}

\author{
José Daniel Amaya CARVAjaL** \\ Deisy Elizabeth CISNEROS IBARRA***
}

\begin{abstract}
RESUMEN. En el presente artículo se sostiene la hipótesis de que el derecho a la promoción horizontal docente para la asignación de horas adicionales en educación básica es un derecho poliédrico que debe ser entendido y aplicado con estrecha interdependencia a los derechos sociales de antigüedad y preferencia en materia laboral. Lo que, de acuerdo con los cánones del constitucionalismo del presente siglo, obliga a interpretarlo, accionarlo y aplicarlo por todas las autoridades educativas, atendiendo a los principios constitucionales de progresividad, interdependencia, indivisibilidad y pro persona en atención a derechos adquiridos y en favor de la calidad educativa.
\end{abstract}

* Recibido el 5 de mayo de 2020 y aceptado para su publicación el 3 de septiembre de 2020.

* Maestro en derecho por la Universidad Autónoma de Nayarit. Actualmente se desempeña como estudiante del Doctorado Interinstitucional en Derecho, organizado de manera conjunta por las universidades públicas del Centro-Occidente de las ANUIES, inscrito en la Universidad de Guanajuato (Generación 2018-2021). Abogado litigante y profesor invitado de la Unidad Académica de Derecho de la Universidad Autónoma de Nayarit.

*** Licenciada en derecho por la Universidad Autónoma de Nayarit. Certificada en el idioma inglés por Cambridge University (B1), Trinity College London (B2) y CENNI (nivel 12) por la Secretaría de Educación Pública. Actualmente es profesora de inglés en Secundaria y perito traductor e intérprete del idioma inglés para el Tribunal Superior de Justicia en el Estado de Nayarit.

\footnotetext{
T) Revista Latinoamericana de Derecho Social Núm. 32, enero-junio de 2021, pp. 95-123
} 
Palabras clave: promoción horizontal, antigüedad y preferencia, calidad educativa, derechos laborales adquiridos.

ABSTRACT: This article supports the hypothesis that the right to horizontal promotion, teacher promotion for the allocation of additional hours, in basic education is a polyhedral right that must be understood and applied with close interdependence to social rights of seniority and preference in labor matters. What in accordance with the canons of the constitutionalism of the present century, forces to be interpreted, activated and applied by all educational authorities, in accordance with the constitutional principles of progressivity, interdependence, indivisibility and pro persona in attention to acquired rights and in favor of the educational quality.

Keywords. Horizontal Promotion, Seniority and Preference, Educational Quality, Acquired Labor Rights.

RÉSUMÉ. Le présent article avance l'hypothèse que le droit à la promotion horizontale, système qui permet d'assigner davantage d'heures de cours aux enseignants titulaires avec rémunération correspondante, de la maternelle jusqu'à la fin du collège, est un droit, sous ses diverses caractéristiques, qui doit être compris et appliqué en corrélation étroite avec les droits sociaux d'ancienneté et de préférence professionnelle. Or, si l'on prend en compte les lois de la Constitution en vigueur au XXI e siècle, toute autorité éducative devrait interpréter ce droit, y avoir recours et l'appliquer en respectant les principes constitutionnels de progressivité, d'interdépendance, d'indivisibilité qui favorisent l'individu («pro persona») en fonction de ses droits acquis afin que son travail puisse être de qualité.

Mots-clés: promotion horizontale, ancienneté et préférence professionnelle, qualité dans l'éducation, droits acquis du travail. 
SUMARIO: I. Introducción. II. El Estado constitucionaly social de derecho en México: su surgimiento y consolidación. III. La teleología de la evaluación docente. IV. La promoción horizontal como un derecho poliédrico. V. Marco jurídico sobre la promoción horizontal en educación básica. VI. Algunas notas procesales sobre la exigibilidad de la promoción horizontal. VII. Retos y perspectivas. VIII. Fuentes de consulta.

\section{INTRODUCCIÓN}

I

a reforma constitucional en derechos humanos de 2011 consignó en el de derecho en México, esquema dentro del cual los derechos humanos son protegidos incluso frente a particulares que detentan poder y, desde luego, en donde no debería haber espacio a violaciones sistemáticas de derechos humanos por parte del Estado. En este esquema, todas las autoridades, en el ámbito de sus respectivas competencias, como parte del Estado se vuelven "aliadas" para proteger derechos humanos mediante un papel más activo, donde no sólo se respeten derechos humanos sino también se promuevan en el conglomerado social.

Así, en ese prototipo de Estado la promoción horizontal en educación básica (promoción para la asignación de horas adicionales), debe ser entendida y aplicada como un derecho poliédrico con estrecha interdependencia a los derechos sociales de antigüedad y preferencia en materia laboral que inexorablemente obliga a todas las autoridades educativas a proteger y promover con progresividad, interdependencia e indivisibilidad, en favor de derechos adquiridos y en aras de consolidar la calidad educativa.

Este derecho social poliédrico que en favor de los docentes en activo consigna la Ley General del Sistema para la Carrera de las Maestras y los Maestros (LGSCMM), y que anteriormente contemplaba la Ley General del Servicio Profesional Docente (LGSPD), no debería ser vista como una disposición que discrecionalmente las autoridades educativas pueden accionar —aun cuando la legislación indebidamente habla de "podra’ — sino más bien como un derecho preferente que debe ser reconocido a docentes en activo.

Es decir, de darse los supuestos normativos que contempla la legislación que regula las evaluaciones docentes, la promoción horizontal debe ser entendida como una obligación para las autoridades educativas y un derecho de preferencia para los docentes en activo. Prerrogativa que debe ser operativizada por el Estado. Pues en un Estado constitucional y social de derecho las 
autoridades tienen la obligación de respetar, promover, proteger y garantizar activamente los derechos humanos y éste no es la excepción. La presente colaboración le permitirá al lector concluir si, en efecto, las porciones normativas sobre la promoción horizontal obligan a la autoridad educativa a interpretar a esta prerrogativa como un derecho poliédrico, y si en efecto existe o existió vacío normativo respecto a la operativización de tal promoción.

Integrado por cinco apartados medulares, el presente estudio refiere en un primer momento a la reforma constitucional de 2011 y su influencia en la consolidación del Estado social en México, donde se subraya que las autoridades educativas del Estado mexicano, como parte de un Estado social, deben tener un papel activo en la promoción y el respeto de derechos humanos; posteriormente, en el apartado denominado la teleología de la evaluación docente, se precisan cuáles son los fines a cumplir por ésta y se destaca la decreciente credibilidad de los procesos de evaluación y el desánimo de los docentes en activo. Luego, se aborda a la promoción horizontal conceptualizándola como un derecho poliédrico, debido al efecto reflejo que tiene en diversos ámbitos del sistema educativo. En seguida se hace un estudio del marco jurídico sobre la promoción horizontal en educación básica, donde se destaca que este derecho ha tenido presencia normativamente, pero no se han elaborado lineamientos o convocatorias que precisen la forma en la que opera. Asimismo, se refieren algunas notas procesales para hacer exigible la promoción horizontal, como meras posibilidades normativas, ya que la legislación al respecto resulta poco clara sobre el medio de impugnación idóneo para hacer valer tal derecho. Finalmente, se esbozan algunos retos y perspectivas en torno a la problemática planteada, que muestran el papel responsable y proactivo que deben jugar las autoridades educativas frente a este derecho.

\section{El Estado CONSTITUCiONAL Y SOCIAL DE DERECHO EN MÉXiCO: SU SURGIMIENTO Y CONSOLIDACIÓN}

$\mathrm{D}$ urante el siglo XX, la exigencia de los derechos sociales alcanzó puntos álgidos derivada de los movimientos revolucionarios que acontecieron en diversas latitudes a largo del planeta. Enfrentamientos armados como los acontecidos en México durante 1910 y años siguientes, resultado de la lucha por el poder, permitieron posteriormente poner en el debate público la necesidad de gestar y consignar de manera escrita derechos de campesinos y trabajadores. Consecuencia de ello, la Constitución de Querétaro de 1917 
expresó las primeras disposiciones constitucionales de derechos sociales, ${ }^{1}$ es decir, reconoció textualmente estos derechos.

Por ello, la Constitución mexicana de 1917 fue un referente obligado, reconocida como un documento de vanguardia ${ }^{2}$ para la construcción del constitucionalismo social de aquella época, que posteriormente fue desarrollado y ampliado por otros países para reclamar derechos de los sectores más desprotegidos de la sociedad. Así, a la Ley Fundamental de Bonn de 1949, se le reconoce como el primer texto donde se consigna constitucionalmente el "Estado social de derecho". ${ }^{3}$

Con todo lo anterior, por citar sólo algunos ejemplos, el derecho a la educación contemplado en el artículo 3o., el interés superior del menor consignado en el artículo 4o., los derechos de los campesinos contemplados en el artículo 27 y, desde luego, los derechos laborales consignados hoy en día en el artículo 123, todos de la Constitución Política de los Estados Unidos Mexicanos, ${ }^{4}$ hacen de nuestra Constitución federal un texto de avanzada en cuanto a reconocimiento de derechos sociales. Sin embargo, conviene puntualizar desde este momento que la esencia de los derechos fundamentales no está en su enunciación sino en su operativización y defensa efectiva. ${ }^{5} \mathrm{Y}$ agregaríamos que, para que a un derecho humano se le respete, primero se le tiene que conocer. Por ello, es válido afirmar que no hay mejor garantía para los derechos que una sociedad alerta y vigilante, que esté dispuesta a exigir sus derechos frente al poder público y privado. ${ }^{6}$

De muy poco (o de nada) nos sirven postulados constitucionales que consignen los derechos de antigüedad y preferencia en materia laboral, por ejemplo, o el derecho a la promoción docente consignado en el artículo 3o., si para ellos no existe un mecanismo eficiente y eficaz que nos permita hacerlos asequibles en nuestra realidad.

1 Carbonell, Miguel, Los derechos fundamentales en México, México, Porrúa-UNAM-CNDH, 2009 , pp. 810 y ss.

2 Vergara Moreno, Benito José, “Los sindicatos frente a las reformas estructurales”, Revista del Instituto de la Judicatura Federal, México, Escuela Judicial, núm. 46, 2018, pp. 57-86.

3 Carbonell, Miguel y Ferrer Mac-Gregor, Eduardo, Los derechos sociales y su justiciabilidad directa, México, Editorial Flores-UNAM, Instituto de Investigaciones Jurídicas, 2014, p. 16.

4 En lo sucesivo también referida como carta magna, CPEUM, Constitución federal o texto constitucional.

5 Valadés, Diego, "La protección de los derechos fundamentales frente a particulares", en Von Bogdandy, Armin et al. (coords.), La justicia constitucional y su internacionalización, México, UNAM-Instituto de Investigaciones Jurídicas, 2010, t. I, pp. 681-710.

6 Carbonell, Miguel y Ferrer Mac-Gregor, Eduardo, op. cit., p. X. 
En ese sentido, en el Estado social de derecho encontramos lo que precisa Luigi Ferrajoli, una especie de "Estado máximo", donde se consignan vínculos y deberes constitucionales para el Estado, con el propósito último de mejorar las condiciones de vida de los ciudadanos. En contraposición con los deberes de no hacer, respetando las autonomías y libertades individuales, que identificaban al "Estado mínimo" o Estado liberal de derecho. ${ }^{7}$ En otras palabras, en el Estado social se maximizan los derechos fundamentales de sectores vulnerables y se busca minimizar el poder público o privado, en la medida de lo posible.

Bajo esas premisas, las reformas constitucionales sobre juicio de amparo y derechos humanos del 6 y 10 de junio de 2011, muestran una teleología de adoptar no sólo una corriente filosófica evidentemente jusnaturalista, ${ }^{8}$ sino también un enfoque social de protección de derechos humanos, al precisarse en el artículo 1o., tercer párrafo, que los derechos constitucionales pueden ser promovidos y protegidos. Enfoque que, incluso, para algunos autores permite hablar de la exigencia horizontal de los derechos humanos; un cambio revolucionario y paradigmático ${ }^{9}$ que traerá resultados ineludibles y turbulentos respecto al sistema de garantías por el cual ha transitado el control de constitucionalidad en México.

En esa línea de ideas, con estos cambios el constitucionalismo mexicano apunta hacia la consolidación del Estado social y, consecuentemente, las autoridades tendrán que realizar acciones para favorecer a que dichos derechos se

7 Ferrajoli, Luigi, "Contra los poderes salvajes del mercado: para un constitucionalismo de derecho privado", trad. de Miguel Carbonell, en Carbonell, M. et al. (coords.), Estrategias y propuestas para la reforma del Estado, 2a. ed., México, UNAM, Instituto de Investigaciones Jurídicas, 2002, pp. 99-110.

8 El jusnaturalismo proviene de aquello que es natural, que ya nos es inherente por el sólo hecho de ser personas, por el hecho de haber nacido y formar parte de una sociedad (aunque ésta aún no se haya formado como Estado), en cambio, el positivismo es aquello que al formarse un Estado se asume como un derecho otorgado por un sistema jurídico formal, y éstos existen porque en alguna legislación han sido plasmados, como una concesión del Estado, en el ejercicio de ese poder público que el pueblo previamente le ha otorgado. Al respecto véanse las obras: García Ramírez, Sergio y Morales Sánchez, Julieta, La reforma constitucional sobre derechos humanos, México, Porrúa-UNAM, 2012, p. 71; Fix-Zamudio, Héctor y Valencia Carmona, Salvador, Las reformas en derechos humanos, procesos colectivos y amparo como nuevo paradigma constitucional, México, Porrúa-UNAM, 2015, pp. 2 y ss.

9 Silva Meza, Juan N., "El impacto de la reforma constitucional en materia de derechos humanos en la labor jurisdiccional en México", Anuario de Derecho Constitucional Latinoamericano, Colombia, Konrad, año XVIII, 2012, pp. 151-172. En línea, disponible en: bttps:// wmw.kas. de/c/document_library/get_file?unid=172b33ad-a9d9-758b-e52c-b33583f8c654\&groupId $=252038$ (9 de diciembre de 2019). 
fortalezcan en la realidad, promoviéndolos y protegiéndolos frente a posibles amenazas que provengan de la sociedad, ${ }^{10}$ es decir, de particulares. Así, el Estado mexicano hoy no sólo debe ser visto como un enemigo de los derechos humanos reconocidos constitucionalmente, sino también como un aliado de la sociedad que debe promover y proteger derechos humanos frente a particulares; lo que identifica a los Estados sociales.

El proteger derechos humanos, como una obligación para el Estado, debe ser entendido como un mandato constitucional proactivo de adoptar todas las medidas necesarias para evitar que otros agentes o sujetos violen derechos (sociales), no sólo a través de los procesos jurisdiccionales sino también a través de esquemas con enfoque preventivo, ${ }^{11}$ que reconozcan que existen ciertos derechos especialmente vulnerables respecto a los cuales resulta justificado implementar ciertas acciones positivas para su realización.

Bajo el anterior argumento, las autoridades del Estado están obligadas a identificar los sectores de la población que podrían estar en desventaja para disfrutar de ciertos derechos, e implementar respecto a ellos los medios más apropiados o pertinentes para hacerlos asequibles. ${ }^{12}$ En términos sencillos, operativizar tales derechos y consignar su mecanismo de defensa ordinario.

$\mathrm{Al}$ respecto, Silva Meza sostiene que los derechos humanos se protegen frente a particulares y, consecuentemente, ello implica aceptar que particulares pueden violar derechos humanos - y con ello violar de forma directa la Constitución-, porque antes tienen el deber de respetarlos. ${ }^{13}$ Por ello la reforma de derechos humanos de 2011, en el tema que aquí nos ocupa representa un avance — desde luego sujeto a interpretación— hacia la consolidación del Estado social de derecho en México, que obliga a todas las autoridades — y entre ellas a las autoridades educativas - a promover, respetar, proteger y garantizar los derechos de los docentes en activo.

Con lo que podemos sostener válidamente que, en el constitucionalismo mexicano del siglo XXI, "la legitimación de los poderes públicos no depende ya solamente de que no entorpezcan o limiten el disfrute de los derechos, sino también de que los promuevan eficazmente". ${ }^{14}$

\footnotetext{
10 Carbonell, Miguel, Los derechos fundamentales en México, cit., pp. 35 y ss.

11 Carbonell, Miguel y Ferrer Mac-Gregor, Eduardo, op. cit., p. 35.

12 Ibidem, pp. 39-41.

13 Silva Meza, Juan N., op. cit., p. 163.

14 Carbonell, Miguel y Ferrer Mac-Gregor, Eduardo, op. cit., p. 13.
} 
Dentro de ese esquema, es insostenible que el Estado y, específicamente, las autoridades educativas dejen de hacer (omitan) en sus políticas públicas el reconocer y garantizar derechos adquiridos a docentes en activo y que excluyan la promoción horizontal; dándole preferencia a la lista de prelación de docentes de nuevo ingreso, quienes de momento sólo cuenta con expectativas de derechos. Pues en todo caso las autoridades educativas con estrecha relación a esta promoción deben interpretar la antigüedad y la experiencia como dos elementos que abonan a la calidad educativa y el interés superior del menor, que permiten preferir a aquéllos respecto a éstos.

Llegados a este punto también conviene referir el papel tan importante que deberían jugar los sindicatos en la exigencia de la promoción horizontal y criticar su actitud omisa (cuando no inclinada a intereses particulares) que permiten la vulneración de derechos adquiridos a favor de docentes en activo que en muchos de los casos ni siquiera han logrado la obtención de una jornada de medio tiempo, cuando es una obligación de los sindicatos el exigir esta promoción a favor de sus representados frente a las autoridades educativas para la dignificación de la profesión docente.

Recordemos que los sindicatos fueron concebidos como parte de esa estructura de pesos y contrapesos en el ejercicio del poder, para garantizar la equidad, las libertades y la dignidad de los trabajadores frente al patrón, todo lo cual en el caso concreto puede ser vulnerado precisamente por la autoridad estatal. Por ello, los sindicatos de trabajadores de la educación deben dimensionar su teleología y estar a la altura de las dinámicas sociales actuales donde además existe una clara tendencia a la ampliación de los derechos humanos, especialmente los sociales, ${ }^{15}$ como los derechos a una educación de calidad, los derechos laborales y la protección del menor.

Luego entonces esta clase de sindicatos como estructuras sociales de poder, en los Estados sociales y democráticos contemporáneos, exige su reconfiguración para que con un enfoque más garantista y atendiendo a la ley del más débil de la que habla Luigi Ferrajoli, ${ }^{16}$ sean responsabilizados en casos concre-

15 Desde el siglo XX, a lo largo de América Latina se han presentado reformas estructurales, todas ellas encaminadas a la ampliación de los derechos previstos en los textos constitucionales, específicamente en derechos sociales. Así lo refieren: Gómez Romo de Vivar, Guillermo Rafael y Olivos Fuentes, Monserrat, "La construcción jurisdiccional de los procesos de consulta de las comunidades indígenas y su aproximación al derecho a la información en México", Revista Derecho del Estado, núm. 45, enero-abril de 2020, pp. 155-185.

$16 \mathrm{Al}$ respecto véase: Ferrajoli, Luigi, Constitucionalismo más allá del Estado, Madrid, Trotta, 2018; id., Derechos y garantías. La ley del más débil, 4a. ed., Madrid, Trotta, 2004; e id., "La esfera 
tos como éstos y la exigencia horizontal de ciertos derechos por parte de sus agremiados sea posible no sólo frente al Estado sino también ante estas esferas pasivas con poder.

La nueva forma de interactuar entre los factores reales de poder ${ }^{17}$ en México muestran que es urgente replantear las reglas del juego en el constitucionalismo mexicano y precisar de nueva cuenta algunas bases constitucionales elementales para recobrar la teleología que tenían los sindicatos en sus orígenes y así, por ejemplo, hacer exigibles ciertos derechos de forma conjunta frente al Estado y entes privados con poder, que no fueron contemplados en el modelo de "Estado de derecho", pero que están presentes en el actual modelo de Estado constitucional social y democrático de derecho, y desde luego se espera de ellos una conducta más activa en favor de sus agremiados. ${ }^{18}$

\section{LA TELEOLOGÍA DE LA EVALUACIÓN DOCENTE}

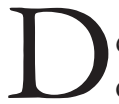
esde el Programa Nacional de Carrera Magisterial, creado en mayo de 1992, el desempeño docente se evaluaba a partir de seis factores: antigüedad, grado académico, preparación profesional, cursos de actualización, desempeño profesional y aprovechamiento escolar e investigación. ${ }^{19}$ Lo anterior no sólo en la búsqueda de la calidad educativa, sino también con el propósito de reconocer a aquellos maestros que comprometidos con el

de lo indivisible y la división de poderes", Estudios Constitucionales, Santiago de Chile, Centro de Estudios Constitucionales de Chile, Universidad de Talca, año 6, núm. 1, 2008.

17 Aquí se hace alusión a la frase empleada por Lasalle, Ferdinand, ¿Qué es una Constitución?, 2a. ed., trad. de Luis Rutiaga, México, Grupo Editorial Tomo, 2013, pp. 51, 59 y 81.

18 Establecer ciertas bases constitucionales a modo de postulados irreductibles respecto a ciertos derechos sociales, para delinear claramente el modelo de Estado democrático — y social— que se aspira tener en la Constitución del Estado mexicano, permitiría exigir la prevalencia del interés público (de la colectividad) y el respeto de ciertos derechos poliédricos en favor de la equidad y la justicia social, por encima del interés propio de ciertos particulares que se valen de las esferas de poder (públicas o privadas) para vulnerar derechos por acción u omisión. Sobre la necesidad de estas bases constitucionales, al menos en lo que concierne al modelo de Estado democrático, véase Gómez Romo de Vivar, Guillermo Rafael, "Armonía jurídica-institucional: una propuesta para la función gubernamental”, en Gómez Romo de Vivar, Guillermo Rafael et al. (coords.), Democracia, gobierno y participación ciudadana, México, Tiran lo Blanch, 2019, pp. 175-193.

19 SEP-SNTE, Comisión Nacional de Carrera Magisterial, Lineamientos generales de carrera magisterial, México, 1998, pp. 17 y ss., disponible en: http://wmw.alianzacivica.org.mx/guia_transparencia/Files/pdf/educacion/14_LINEAMIENTOSOBRECARRERAMAGISTERIAL/LINEAMIENTOS_CARRERA_MAGISTERIAL.pdf (consultado el 6 de diciembre de 2019). 
sistema lograban cubrir todos estos rubros y de ese modo demostraban su contribución al incremento de los índices de la calidad educativa. Es decir, las evaluaciones tenían dos fines a cumplir: incrementar la calidad educativa y reconocer la carrera y desempeño de profesores en activo.

Lo anterior de algún modo mostraba el sentido de responsabilidad por parte del Estado en reconocer la digna e importante labor que los profesores en educación básica realizan, respetando sus derechos laborales adquiridos, derechos sociales que, de cubrir con los rubros anteriormente mencionados, desde luego, le generaban derechos al gobernado y en contrapartida obligaciones para las autoridades educativas.

Esa evaluación multifactorial con la que ya contaba el Programa Nacional de Carrera Magisterial era acorde incluso con la dinámica que se presentaba a nivel internacional, en el sentido de evaluar de diversas formas la calidad educativa. Lo que incluso hasta 2007, permitía apreciar que al menos cincuenta países de América y Europa ya identificaban ocho procedimientos de evaluación: observación en el aula; entrevistas a los profesores; informe de la dirección del centro escolar; pruebas estandarizadas para medir habilidades básicas, conocimientos pedagógicos y académicos; portafolio del profesor; pruebas de rendimiento de los alumnos; cuestionarios dirigidos a los alumnos o sus familias; y autoevaluación. ${ }^{20}$ Circunstancias todas ellas que, evidentemente, permitían mostrar la idoneidad de algún profesor en activo para ocupar una vacante en su propio plantel educativo o en lugar cercano al mismo, de cubrir todos estos rubros de evaluación antes de preferir a un profesor de nuevo ingreso.

Si en ese proceso evaluativo se distorsionó el propósito que buscaba el Prograna Nacional de Carrera Magisterial, no fue por motivo de la norma, como tampoco fue por el docente, sino en todo caso fue resultado de las malas prácticas de las estructuras de poder que permitían que personas no idóneas o sin el perfil deseado llegaran a beneficiarse con plazas u horas adicionales.

Sin embargo, con las reformas de 2013 al sistema educativo y más precisamente a los procesos de evaluación docente, esto no fue entendido así. Y se vulneraron abiertamente derechos adquiridos al darle un enfoque a dicha reforma sólo de obligaciones para los docentes en activo "en favor de la calidad educativa" y no verla como una posibilidad de oponer derechos adquiridos.

20 Murillo Torrecilla, F. Javier (coord.), Evaluación del desempeño y carrera profesional docente. Un estudio comparado entre 50 paises de América y Europa, Chile, ONU-UNESCO-Ministerio de Educación y Ciencia en España, 2007, pp. 102 y 103. Disponible en: https:/ / unesdoc.unesco.org/ ark:/48223/pf0000152934 (consulta realizada el 6 de diciembre de 2019). 
En otras palabras, no pasa inadvertido que la mala interpretación de la Ley General del Servicio Profesional Docente (LGSPD) propició que una sola evaluación —al menos en Nayarit— les permitió a muchos docentes de nuevo ingreso, incluso sin formación pedagógica, generar mayores derechos y la obtención de un mayor número de horas en menos tiempo que docentes en activo con extensa experiencia pedagógica, formación profesional nada despreciable, actualizaciones constantes y antigüedad en educación básica. Con lo que se evidenció una clara inequidad y un total desentendimiento a garantizar a la infancia una educación de calidad, por parte de las autoridades educativas locales.

En síntesis, a través de una evaluación que no fue multifactorial se pretendió hacer frente a un problema social: la consolidación de la calidad educativa en educación básica, desestimando que regionalmente ya ha sido reconocida como un fenómeno multifactorial.

La existencia de estudios regionales previos a la reforma de 2013, tendentes a demostrar que el problema de la calidad educativa es una cuestión multifactorial ${ }^{21}$ no fueron tomados en cuenta para distinguir entre docentes de nuevo ingreso (sin experiencia docente y sin formación pedagógica) y docentes en activo. Las evaluaciones docentes en México durante la vigencia de la LGSPD se llevaron a cabo tomando en cuenta sólo una lista de prelación en atención al resultado de un examen.

Con lo que, desde luego más allá del discurso político, la reforma educativa de 2013 y la LGSPD, sí repercutió en la situación laboral de muchos docentes en activo. Como resultado de una evaluación, algunos se quedaron sin empleo y muchos otros vieron cómo les arrebataban su oportunidad de crecimiento en el plantel educativo donde actualmente laboran.

La inconformidad, la falta de credibilidad en las evaluaciones y el desánimo de docentes de educación básica frente a estos cambios encuentra plena justificación. ${ }^{22}$ Pues contradictoriamente, los resultados negativos de las eva-

21 Peralta, Victoria, "El bienestar como fin para la construcción de la calidad en la educación de la primera infancia”, en Peralta, Victoria y Hernández, Laura (coords.), Antología de experiencias de la educación inicial iberoamericana, Madrid España, OEI-Unisef-BBVA, 2012, pp. 9-21, disponible en: https://guao.org/sites/default/files/biblioteca/Antolog\%C3\%ADa\%20de\%20 experiencias $\% 20 d e \% 20 \mathrm{la} \% 20$ educaci $\%$ C3\%B3n\%20inicial\%20iberoamericana.pdf (consulta realizada el 5 de diciembre de 2019).

22 Un estudio sobre la desilusión, la falta de credibilidad en las instancias evaluadoras y las autoridades, así como el temor ante la incertidumbre laboral, por parte de los docentes, se llevó a cabo en Baja California, y esa percepción no dista mucho de la opinión que se tiene en Nayarit. Al respecto, véase Martínez Lobato, Lilia et al., Reforma educativa y profesores, Percepción 
luaciones docentes (que además eran acumulables) justificaban un despido, pero, los resultados positivos (que tenían periodo de vencimiento y no se acumulaban) bien podían no reflejar ningún beneficio.

Adicionalmente, la interpretación que se le dio a la lista de prelación que consignó la LGSPD debe ser vista como una aberración jurídica, pues permitió (de la forma más fácil) la asignación de plazas o en su caso el otorgamiento de horas vacantes a personas de nuevo ingreso (incluso sin formación pedagógica) que fueron "mejores candidatos" que docentes en activo para ocupar horas vacantes por la sola diferencia de un par de puntos. Es decir, contrario a toda una lógica jurídica no se hacía la distinción entre docentes de nuevo ingreso y docentes en activo, como si se tratara de una subasta o de una rifa en donde todos podían participar. Lo que no tenía relación directa en nada con la calidad educativa, antes bien la mercantilizó.

Con lo anterior, quedó probada aquella afirmación que sostiene que: "el poder no se crea ni se destruye, sino sólo se transforma", pues las distorsiones que se habían dado en sede sindical (y se buscaban evitar a través de la reforma de 2013) pasaron a reproducirse en las instancias educativas que actualmente tienen total injerencia en la asignación de plazas y horas vacantes.

Ahora bien, si hoy se sabe que la calidad educativa es un fenómeno multifactorial, entonces lo correcto sería que dichas evaluaciones también se llevaran a cabo a través de diversos rubros a evaluar. Desde luego, partiendo de la premisa básica de que profesores de nuevo ingreso y los docentes en activo no están en igualdad de condiciones, pues a estos últimos les asiste su antigüedad, su experiencia y la actualización en su ejercicio profesional diario como docentes. Diferenciación que, en pos de la calidad educativa, debió matizarse desde las propias convocatorias, pero no se hizo.

En tal sentido, para recobrar el fin que buscan las evaluaciones docentes, sería conveniente que las convocatorias para la promoción y la oposición para el nuevo ingreso se llevaran a cabo en periodos distintos en donde la promoción horizontal se anticipe a la asignación de plazas y horas vacantes a personas de nuevo ingreso; para con ello garantizar que los espacios que sean ofertados a oposición (para nuevo ingreso) no tengan un derecho preferente por parte de un docente en activo.

Adicional a lo anterior, valdría la pena considerar la posibilidad de que la evaluación docente en todas sus modalidades $-\mathrm{y}$ no sólo la promoción

sobre los procesos de evaluación, San Luis Potosí, XIV, Congreso Nacional de Investigación Educativa, 2017. 
horizontal que aquí se estudia — se llevara a cabo por instituciones con credibilidad e imparcialidad probada como el Centro Nacional de la Evaluación (Ceneval). Evaluaciones en las cuales los cuestionamientos sean lógicos, racionales, acordes a los contextos docentes de cada región del país. Con preguntas respecto a la materia que se imparte y al conocimiento que se espera transmitir. Esto daría una mayor confianza al proceso de evaluación y asignación de plazas.

En el mismo sentido sería conveniente la trasparencia de los espacios disponibles a través de una plataforma que permita visualizar las plazas y horas vacantes de los planteles en las entidades federativas de ciclos próximos (al menos para los docentes que ya forman parte del sistema educativo), con el propósito de que docentes en activo prevean su postulación por reunir multifactorialmente el perfil requerido.

Bajo ese bosquejo, se recobraría la confianza de los docentes en activo hacia las evaluaciones docentes, se reconocerían sus derechos adquiridos, se preferiría justificadamente la experiencia docente y el conocimiento pedagógico y, desde luego, se contribuiría a la calidad educativa. Es decir, sería un diseño de evaluación docente donde todos ganen.

\section{LA PROMOCIÓN HORIZONTAL COMO UN DERECHO POLIÉDRICO}

\section{L}

a Reforma Educativa llevada a cabo por el gobierno mexicano, durante los niños y jóvenes a recibir una educación de calidad, olvidando a otro actor del sistema educativo de suma importancia: el docente en activo. El cual no sólo debe ser visto como portador de obligaciones, responsable de la "calidad educativa", sino también como sujeto de derechos, el cual debe ser respetado y protegido por la autoridad educativa.

Existen tres tipos de promoción en educación básica: 1) la promoción a cargos con funciones de dirección y supervisión (promoción vertical); 2) la promoción en la función (incentivos), y 3) otras promociones en el servicio, donde entran las funciones de asesoría técnica pedagógica y la promoción para la obtención de horas adicionales (promoción horizontal).

Estas evaluaciones tendrían que ir ligadas con la teleología de las reformas educativas de 2013 y 2019 las que — según el discurso político— propician la calidad educativa para los estudiantes de educación básica, a través de la asignación de las horas frente a grupo a los mejores perfiles docentes existen- 
tes para ocupar plazas u horas vacantes. Haciendo una clara distinción entre docentes en activo y docentes de nuevo ingreso, como resulta propio de la interpretación sistemática y armónica de los diversos artículos que componen la legislación aplicable.

No pasa inadvertido que tanto la Ley General del Sistema para la Promoción Docente (LGSPG) como la actual Ley General del Sistema para la Carrera de las Maestras y los Maestros (LGSCMM), contemplaron como uno de sus fines el revalorizar y reconocer la experiencia y antigüedad de los docentes en activo, a través de una carrera justa y equitativa que permitiera, conjuntamente con la calidad educativa, el desarrollo profesional de las maestras y los maestros que ya pertenecen al sistema educativo. Lo que tiene estrecha relación o interdependencia con la antigüedad y preferencia que se consigna en el artículo 123 de la Constitución federal, como un derecho social en materia laboral para buscar la equidad y reciprocidad en las relaciones laborales.

Con lo anterior, se patentiza que la promoción horizontal se instauró precisamente para privilegiar a los docentes que ya cuentan con experiencia y antigüedad, cuyo propósito es mejorar la calidad educativa y también su condición laboral. Lo que, además, atiende al principio de progresividad en materia de interpretación de los derechos humanos.

El optar preferentemente por docentes que ya cuentan con experiencia y antigüedad en el sistema resulta lógico, porque ellos ya están arraigados a las prácticas docentes y a las técnicas aplicadas de enseñanza-aprendizaje que son más afines a los entornos y contextos de donde se desenvuelven profesionalmente. De ahí que no sea correcto considerar a los profesores de nuevo ingreso en igualdad de oportunidades frente a los docentes en activo, pues a estos últimos les asiste su antigüedad en el sistema educativo y a los primeros sólo la eventualidad de un buen resultado en un examen de oposición.

La promoción docente para la obtención de horas adicionales es un derecho "poliédrico", porque su activación o ejecución repercute en distintas vertientes encaminadas a regular distintos aspectos de los procesos de evaluación docente y el sistema educativo.

Por un lado puede interpretarse como una "regla de trato preferente" hacia los docentes en activo, que deben ser tomados en cuenta antes que los de nuevo ingreso para ocupar horas vacantes de reunir el perfil docente necesario y haber obtenido resultado favorable en su evaluación para horas vacantes en un mismo plantel o lugar cercano y, por otro lado, puede manifestarse como una "pauta para la calidad educativa", al ayudar a discernir en supuestos espe- 
cíficos donde haya dos o más maestros que puedan reunir el perfil requerido, para optar por aquellos con mayor antigüedad y arraigo al sistema educativo.

Aunado a lo anterior, este derecho poliédrico evita la fragmentación de horas y contribuye a la compactación de la carga horaria de los docentes en un solo plantel educativo preferentemente, o en lugares cercanos; lo que desde luego contribuye a un mejor rendimiento de los docentes, a una dedicación exclusiva al sistema educativo, a un mayor arraigo a un plantel educativo y a la comunidad cercana; todo ello propicia una mayor calidad educativa.

Ahora bien, si se realiza un análisis crítico de la jurisprudencia que respecto al servicio profesional docente ha emitido la Suprema Corte de Justicia de la Nación (SCJN), podemos decir que las evaluaciones docentes han sido —indebidamente- estudiadas sólo como generadoras de obligaciones y consecuencias para el docente. Cuando también es cierto que, de obtener resultados favorables y reunir con el perfil idóneo, deberían de reconocerse derechos oponibles frente las autoridades educativas. En ese sentido, hay un vacío jurisprudencial respecto a derechos adquiridos en esta temática.

$\mathrm{Al}$ respecto, el Pleno de la SCJN ha señalado que "la estabilidad en el empleo no es absoluta" y que los docentes pueden ser "suspendidos o cesados por causa justificada" de no aprobar la evaluación a la que son sujetos obligatoriamente. ${ }^{23}$ Sin embargo, bajo ese mismo esquema, debió de haberse precisado que aprobar satisfactoriamente —o de forma sobresaliente— esas mismas evaluaciones deben traducirse en derechos a favor de los docentes en activo y, paralelamente, deben traer consigo obligaciones para las autoridades educativas.

En esa misma línea argumentativa, favorable sólo para el Estado, el Pleno de la Suprema Corte de Justicia de la Nación además ha sostenido que la reforma al artículo 3o. constitucional, publicada en el Diario Oficial de la Federación el 26 de febrero de 2013, "implementó un nuevo sistema de evaluación obligatoria para el ingreso, promoción y permanencia en el servicio del personal docente, con la finalidad de crear un nuevo modelo educativo que asegure la calidad en el servicio y, con ello, tutelar también el interés superior del menor" que "justifica plenamente la separación de los docentes de su empleo cuando no acrediten las evaluaciones". ${ }^{24}$

23 Gaceta del Semanario Judicial de la Federación, SCJN, Pleno, tesis P./J. 31/2015 (10a.), constitucional, laboral, septiembre de 2015, 1. 22, t. I, p. 8.

24 Gaceta del Semanario Judicial de la Federación, SCJN, Pleno, tesis P./J. 34/2015 (10a.) y P./J. 35/2015 (10a.), constitucional, laboral, septiembre de 2015, 1. 22, t. I, pp. 9 y 12. 
Pero qué pasa cuando un docente en activo cumple con todas sus obligaciones, obtiene buenos resultados en sus evaluaciones, cuenta con experiencia y antigüedad demostrables pero no obtiene beneficio alguno; no es promovida y por el contrario ve cómo personas de nuevo ingreso logran más y en menos tiempo. ¿Será eso la calidad en el servicio a la que se refiere el máximo tribunal de México? ¿Será propio de un Estado constitucional y social de derecho? La argumentación de la SCJN sólo habla de obligaciones para los docentes, pero no habla de derechos, lo que es lamentable para el reconocimiento y tutela de derechos sociales de este sector laboral tan importante para el desarrollo del Estado.

A partir de estos argumentos, se afirma que la promoción docente para la obtención de horas adicionales o también conocida como promoción horizontal, debe ser interpretada como un derecho poliédrico que debe ser respetado, promovido y garantizado por las autoridades educativas. Lo que puede ser posible a través de políticas públicas de educación que reconozcan que los docentes en activo tienen un derecho de preferencia respecto a los docentes de nuevo ingreso.

Ahora bien, la actuación del sindicato en la promoción docente debería ser proactiva, decidida y contundente. Pues los sindicatos fueron concebidos para representar, precisamente, los intereses de sus sindicalizados. En teoría, esta estructura gremial debería ser la trinchera desde donde se reclamara la preferencia para docentes en activo con resultados favorables en evaluaciones y horas vacantes en su propio plantel o lugar cercano, como aun lo señala la legislación aplicable.

Sin embargo, la violación a derechos humanos por los sindicatos a través de una actitud omisa y pasiva durante la vigencia de la Ley General del Servicio Profesional Docente fue muy latente. Pues muy poco (o nada) se exigió ante las autoridades educativas correspondientes. De tal suerte que los concursos de oposición sólo sirvieron para posicionar — bajo el consenso del patrón y el sindicato - en los mejores lugares de la lista de prelación a conocidos y amistades, aun en detrimento de derechos adquiridos de docentes en activo que debieron de haber sido promovidos en forma preferente frente a personas de nuevo ingreso. ${ }^{25}$

25 En Nayarit, muchas de estas irregularidades fueron denunciadas incluso mediante manifestaciones de docentes (en activo con años de servicio) ante el gobernador del estado, pidiendo la transparencia de los concursos de oposición y la destitución de ciertos funcionarios públicos de Servicios de Educación Pública del Estado de Nayarit (SEPEN) que mostraban un claro interés en las plazas existentes en planteles cercanos a la capital del estado, donde 
En otras palabras, aun cuando había posibilidades de promover docentes en activo en casos concretos en Nayarit, que reunían el perfil docente y tenían resultados favorables en sus evaluaciones, se optó por favorecer a personas de nuevo ingreso. Bajo el argumento de que las evaluaciones de oposición no eran para efecto de ser promovidos, pero ¿se lanzaron convocatorias para la promoción horizontal durante la vigencia de la LGSPD? No, ninguna. Y con ello se violentaron sistemáticamente derechos adquiridos y se actuó también en detrimento de la calidad educativa de los educandos. Es decir, los docentes en activo que exigían ser promovidos al estar en dicho supuesto normativo se vieron en total indefensión, al carecer de lineamientos o convocatorias particulares que permitieran hacer operativa su promoción horizontal. Una violación evidente a la ley por parte de las autoridades educativas.

\section{MARCO JURÍDICO SOBRE LA PROMOCIÓN HORIZONTAL EN EDUCACIÓN BÁSICA}

E n el presente apartado, se hablará de la Ley General del Servicio Profesional Docente (abrogada) y de la Ley General del Sistema para la Carrera de las Maestras y los Maestros (vigente), para dar un panorama de ambas legislaciones y la consignación en las mismas de la promoción horizontal que, aun cuando se encuentra prevista en la norma, durante la vigencia de dichas legislaciones no se ha implementado. Es decir, hasta el momento la autoridad educativa en Nayarit no ha lanzado convocatorias, lineamientos o reglamento alguno que le dé operatividad a tal derecho para los docentes en activo durante todo este tiempo.

\section{La Ley General del Servicio Profesional Docente}

Es importante partir de una premisa básica; por disposición expresa, la LGSPD disponía que era la normativa que servía para regir al Servicio Profesional Docente y establecer los criterios y condiciones para el ingreso, la promoción, el reconocimiento y la permanencia en dicho Servicio. ${ }^{26}$ Teniendo

aun cuando ya se contaba con profesores que reunían el perfil requerido y habían obtenido resultados favorables en la evaluación, no fueron promovidos en los términos de los artículos 23, último párrafo, 42, 52 y 63 de la Ley General del Servicio Profesional Docente (LGSPD).

26 Artículo 1o., primer párrafo, de la Ley General del Servicio Profesional Docente (LGSPD). 
por objeto, el regular los derechos y obligaciones derivados del Servicio Profesional Docente, así como asegurar la transparencia y rendición de cuentas en el Servicio Profesional Docente. ${ }^{27}$ Nótese que el Servicio Profesional Docente podría traer como consecuencia derechos de acuerdo con la legislación.

Ahora bien, según lo señalaba su artículo 4o., fracción IV, la autoridad educativa local era entendida como el ejecutivo de cada una de las entidades federativas, es decir, el gobernador del estado quien por obviedad de razones cuenta con facultades para pedirle rendición de cuentas a su vez al secretario de Educación Pública de la entidad que corresponda. El extenso contenido del artículo 4o., entre otras cosas, contemplaba en su fracción XXVII, el tema de la promoción docente y ahí indicaba que por ésta debía entenderse el acceso a una categoría o nivel docente superior al que se tenía; lo que, desde luego, en el caso de los docentes que no eran de jornada, debía interpretarse como la posibilidad de obtener más horas en términos de los artículos 23, último párrafo, 42 y 63 de la citada Ley.

Llama mucho la atención los principios éticos contenidos en el artículo 5o. de la LGSPD, que en todo caso debieron de haber sido atendidos en todo momento por las autoridades educativas locales, durante la aplicación y vigencia de la Ley en comento, como la legalidad, la certeza, la imparcialidad, la objetividad y la transparencia.

De acuerdo con el artículo 7o., fracciones VI, XIV y XVI, de la Ley en comento, correspondía al Instituto Nacional para la Evaluación de la Educación (actualmente inexistente), "supervisar los procesos de evaluación y la emisión de los resultados previstos en el Servicio, la administración y asignación de plazas y, en general, el emitir los actos jurídicos que crearan, declararan, modificaran o extinguieran derechos y obligaciones de conformidad a la normativa".

El artículo 13 de la LGSPD contemplaba como uno de los propósitos del Servicio, el "estimular el reconocimiento de la labor docente mediante opciones de desarrollo profesional y el reconocimiento escolar y social de la dignidad magisterial". Algo que, desde luego, tiene estrecha relación con la promoción docente, en el sentido de dignificar su labor a través de un reconocimiento preferentemente en el mismo plantel o la compactación de horas, de la que se hablará en líneas posteriores.

Por su parte, el artículo 23 de la LGSPD, al establecer las bases para la asignación de plazas, en su último párrafo contemplaba que, tratándose de horas

27 Artículo. 2o., fracciones III y IV (LGSPD). 
y no plazas, las autoridades educativas y los organismos descentralizados no tenían la necesidad de atender las listas de prelación para la asignación de dichas horas, sino en todo caso el contenido del artículo 42 de la misma normativa que contempla lo concerniente a la promoción horizontal de docentes en activo. Es decir, la asignación de horas adicionales para aquellos profesores que cuentan con pocas horas base, para mejorar su condición de trabajo y, desde luego, su ingreso.

La promoción horizontal, uno de los tres tipos de promoción existentes en la legislación en comento, se contemplaba en el artículo 42, donde señalaba que tanto en Educación Básica como en Media Superior para la asignación de horas adicionales de los docentes que no fueran de jornada, se debía considerar una promoción, en donde los docentes, para su obtención, debían:

- reunir el perfil requerido para las horas disponibles, y

- obtener en la evaluación del desempeño un resultado que sea igual o superior al nivel requerido por las autoridades educativas. ${ }^{28}$

Este tipo de promoción, por disposición expresa, debía tener lugar en los casos siguientes:

- en el mismo plantel en que el docente prestara total o principalmente sus servicios;

- en el plantel en que el docente no prestara principalmente sus servicios, siempre y cuando hubiera compatibilidad de horarios y distancias con el plantel donde principalmente prestaba sus servicios y, adicionalmente, no tuviera horas asignadas en un tercer plantel, y

- en un plantel en que el docente no prestara sus servicios, siempre y cuando se tratara de horas fraccionadas, en el numero que determine la autoridad educativa o el organismo descentralizado, y en dicho plantel no exista personal que cumpla con lo establecido en las fracciones I y II del artículo en comento.

Para lo cual las autoridades educativas competentes estaban obligadas a fijar las reglas necesarias para seleccionar al personal docente que recibiera la promoción en comento, cuando hubiera más de uno que cumpliera con los

28 Sobre el particular es conveniente precisar que aun el informe individual de resultados del concurso de oposición habla de un desempeño, motivo por el cual para los docentes en activo el resultado de dicha evaluación podía considerarse para efectos de una promoción. 
requisitos establecidos. Sin embargo, en la práctica esto nunca se llevó a cabo al menos en Nayarit, pues durante la vigencia de la LGSPD llama la atención por su ausencia cualquier convocatoria o lineamientos al respecto que hicieran posible esta promoción horizontal.

Esta promoción para la obtención de horas adicionales refería la evaluación del desempeño docente, contenida en el artículo 52 de la LGSPD, sin embargo, ¿qué pasó con aquellos maestros que — curiosamente - no eran evaluados para su desempeño y se presentaba el supuesto de haber horas vacantes acordes a su perfil en el plantel donde laboraban? Pasaba que, dichas horas eran ofertadas a concurso de oposición y eventualmente venía un profesor de nuevo ingreso a ocuparlas, en flagrante violación al sentido teleológico del artículo anteriormente referido.

La promoción docente por horas adicionales, evidentemente, perseguía un fin: el reconocer los derechos adquiridos de los docentes en activo, lo que tiene orden preferente. Además, encuentra estrecha relación con derechos como la antigüedad y la preferencia. La anterior aseveración se ve patentada además por el contenido del artículo 63 de la LGSPD, que contempla en cuanto obligación para las autoridades educativas el evitar la asignación fragmentaria de horas y buscar en todo momento la compactación de éstas, lo que no podría ser de otro modo sino respetando la antigüedad y la preferencia.

En otras palabras, preferentemente, por disposición expresa las autoridades educativas, debían observar que los profesores en activo incrementaran horas en su propio plantel educativo o en lugar cercano y, en su caso, fomentar la compactación de horas en un mismo plantel. Lo que adquiere sentido junto con la promoción, para el reconocimiento de derechos preferenciales de los docentes en activo respecto a aquellos docentes de nuevo ingreso. Sería un absurdo pensar en beneficiar a una persona de nuevo ingreso, antes de dignificar y mejorar la situación laboral de quienes ya forman parte del sistema educativo; un absurdo que en la práctica se presentó en más de una ocasión y ello lo demuestra esa ausencia de convocatorias o lineamientos al respecto que hicieran posible la promoción horizontal. Un desinterés de la estructura del Estado a nivel local que, violentó flagrantemente derechos humanos y que vulneró la obligación consignada en el artículo 1o., segundo y tercer párrafo de la Constitución federal, al no respetar, promover y garantizar este derecho poliédrico. 


\section{La Ley General del Sistema para la Carrera de las Maestras y los Maestros}

Como resultado de la reforma constitucional del 15 de mayo de 2019, la Ley General del Sistema para la Carrera de las Maestras y los Maestros (LGSCMM) consigna dentro de su objeto el revalorizar a las maestras y maestros como profesionales de la educación, con pleno respeto a sus derechos, y el regular los procesos de selección para la admisión, promoción y reconocimiento del personal que ejerza la función docente, directiva o de supervisión. Este análisis sólo se concentrará en lo que respecta a la promoción docente para la obtención de horas adicionales (promoción horizontal).

En el artículo 7o., fracción II, la LGSCMM, reconoce — de nueva cuenta- como autoridad educativa de las entidades federativas al Ejecutivo de cada uno de los estados; quienes de una interpretación sistemática y armónica de los artículos 8o., 10, 14 y 15, tienen la obligación con las maestras y los maestros de hacer asequible el acceso a una carrera justa y equitativa, promoviendo su desarrollo de acuerdo con sus conocimientos, aptitudes y experiencia. Lo que incluso, en caso de irregularidades cometidas por servidores públicos, de conformidad con el artículo 18 de la LGSCMM, da espacio a medidas correctivas.

Esto se trae a cuento debido a que, todo ese marco normativo refleja la intención del legislador de que las autoridades educativas en el ámbito de sus respectivas competencias implementen políticas públicas a efecto de hacer reales no sólo las obligaciones de los docentes en activo sino también sus derechos adquiridos; uno de esos derechos es el derecho a la promoción horizontal.

Bajo esa línea argumentativa, debe destacarse que el diverso artículo 32 de la LGSCMM consigna una obligación (un deber) para el director o la directora de cualquier plantel educativo de educación básica, de notificar al titular de dicho nivel educativo respecto a las horas o plazas vacantes que surjan durante el ciclo escolar. Una porción normativa de la que carecía la legislación previa y que afortunadamente contempla la legislación vigente de la materia.

Adicionalmente, por disposición expresa, se refiere que lo consignado en dicho artículo deberá ser tomado en cuenta en los procesos de promoción. Con lo que, evidentemente, se busca preferir la promoción de los profesores que ya se encuentran en activo y forman parte del sistema educativo, antes que la contratación de personas de nuevo ingreso.

Prioridad que, es lógico pensar, también es observada en los procesos de admisión al considerar preferentemente a los profesionistas con formación 
pedagógica, tal como lo consigna el artículo 40, segundo párrafo, de la Ley en comento. Es decir, ahora válidamente, aun en los procesos de admisión como otra especie resulta plenamente justificado el preferir a aquellas personas que cuenten con formación profesional para dar clase, es decir, con conocimientos y experiencia pedagógica. De algún modo, esto ayuda a que la educación en nivel básico y media superior no se "mercantilice" como se estuvo haciendo durante la vigencia de la anterior Ley; producto de una mala interpretación de la norma, al abrir las puertas a diversidad de profesionistas que con buenos resultados en las evaluaciones de oposición ("meras eventualidades") arrebataron la oportunidad de crecimiento a muchos profesores que ya formaban parte del sistema, aun cuando estos últimos, desde luego, demostraron ser idóneos en las mismas evaluaciones. Profesionistas que, por cierto, fueron formados para atender a las necesidades de las niñas, niños y adolescentes (NNA), y de ahí el privilegiar la formación pedagógica, pero que, por azares del destino, no lograron posicionarse en los primeros lugares de esa misma "lista de subasta" para ser preferidos, y así perdieron por ejemplo la consideración a obtener horas vacantes en sus propios planteles educativos.

Finalmente, conviene destacar que en términos muy parecidos a como lo contemplaba la LGSPD, ahora los artículos 55 y 56 de la LGSCMM consignan la promoción docente para la asignación de horas adicionales. Sin embargo, lo que sería loable es que las autoridades educativas locales respeten, y no sólo esté consignada como buenas intenciones que en la práctica resulta ser mera letra muerta.

El artículo 55 de la Ley en cita, refiere que será la Secretaría de Educación Pública la que emita las disposiciones aplicables para la asignación de plazas por horas-semana-mes en la modalidad de promoción. Es decir, de nueva cuenta se contemplan "disposiciones aplicables", ya sea una convocatoria, lineamientos o manuales de operación para hacer operativa esta promoción docente. Se espera que esta vez sí se elaboren, por el bien de los docentes en activo que tienen el deseo de crecer horizontalmente a través de la obtención de horas adicionales.

Finalmente, es de reconocerle a esta nueva legislación el hecho de que haya contemplado en el último párrafo de su artículo 56, que ante la posibilidad de que haya más de un docente que reúna los requisitos de ley, las autoridades se verán obligadas a seleccionar al docente que cuente con mayor antigüedad, lo que concuerda con la línea argumentativa que aquí se sostiene. Y se trata de una porción normativa que no contemplaba la anterior Ley. 


\section{AlgunAS NOTAS PROCESALES SOBRE LA EXIGIBILIDAD}

DE LA PROMOCIÓN HORIZONTAL

$O^{i}$ i la esencia de los derechos fundamentales, como escribe Diego Valadés, no está en su enunciación sino en su defensa efectiva, no es posible hablar de cuestiones sustanciales sin mostrar el aspecto procesal para conocer la defensa de los derechos fundamentales de los que se hable en particular. En el caso concreto, la promoción docente para la asignación de horas adicionales en educación básica requiere al menos una referencia breve de la vía a través de la cual es posible su exigencia.

Por ello, en este apartado se pretende mostrar de forma telegráfica las posibilidades procesales de reclamar la promoción horizontal en la vía laboral; en la vía administrativa y, en su caso, a través del juicio de amparo indirecto. Todo ello para comprender ante qué autoridad competente acudir de encontrarse ante una eventual violación a tal derecho de promoción horizontal entendida como un derecho poliédrico con estrecha relación con la antigüedad y preferencia (en materia laboral) y el interés superior del menor a una educación de calidad.

\section{La vía laboral como solución al problema}

La Constitución Política de los Estados Unidos Mexicanos, como referente medular en materia laboral, contempla en su artículo 123 la distribución de competencia laboral en dos grandes vertientes, atendiendo a la naturaleza de la relación laboral trabajador-patrón. Por una parte, el artículo 123, apartado A, que a su vez es reglamentado por la Ley Federal del Trabajo, contempla lo concerniente a las relaciones laborales que surgen entre particulares. Lo que de forma general les corresponde a las autoridades de las entidades federativas, es decir, a las Juntas Locales de Conciliación y Arbitraje en sus respectivas jurisdicciones; pero es de la competencia exclusiva de las autoridades federales, es decir, de las Juntas Federales de Conciliación y Arbitraje, tratándose de los asuntos contemplados en la fracción XXXI del artículo 123, apartado A, de la Constitución federal.

Aunque conviene precisar que debido a una reforma constitucional en materia laboral de 2017, ${ }^{29}$ próximamente se hablará en lugar de juntas (locales y

29 Al respecto véase el decreto de reforma constitucional del 24 de febrero de 2017, por 
federales) de tribunales laborales de las entidades federativas o del Poder Judicial de la Federación, según corresponda. ${ }^{30}$ Los que pertenecerán al Poder Judicial local ${ }^{31}$ y federal, y no al Poder Ejecutivo como actualmente están estructurados.

Luego, reguladas en el artículo 123, apartado B, de la Constitución Política de los Estados Unidos Mexicanos, encontramos las relaciones laborales que surgen entre los poderes de la Unión y sus trabajadores, es decir, las relaciones burocráticas federales. Lo que, a su vez, con mayor precisión, es reglamentado por la Ley Federal de los Trabajadores al Servicio del Estado. Los conflictos laborales de esta naturaleza, de acuerdo con la fracción XII del apartado y artículo constitucional en comento, son sometidos a un Tribunal Federal de Conciliación y Arbitraje. Asimismo, conviene delimitar que los conflictos entre el Poder Judicial de la Federación y sus servidores son resueltos por el Consejo de la Judicatura Federal, y los que se suscitan entre la Suprema Corte de Justicia y sus empleados son resueltos por esta última.

Finalmente, por disposición expresa del artículo 116, fracción VI, de la Constitución Política de los Estados Unidos Mexicanos, tenemos reguladas las relaciones de trabajo entre los estados y sus trabajadores. Disposición que a su vez remite a los postulados contenidos en el diverso artículo 123 y lo que las legislaturas locales consignen en las disposiciones reglamentarias correspondientes. Lo que en el caso concreto de Nayarit, se reglamentaba a través del Estatuto Jurídico de los Trabajadores al Servicio del Estado de Nayarit y que, recientemente, por reforma del 31 de mayo del 2019, fue sustituido por la Ley Laboral Burocrática del Estado de Nayarit, ${ }^{32}$ en donde, actualmente, es autoridad competente para conocer el Tribunal de Conciliación y Arbitraje en

el que se declaran reformadas y adicionadas diversas disposiciones de los artículos 107 y 123 de la Constitución Política de los Estados Unidos Mexicanos, en materia de justicia laboral.

$30 \mathrm{Al}$ respecto véase el artículo 123, apartado B, fracción XX, de la Constitución Política de los Estados Unidos Mexicanos, reformado con fecha 24 de febrero de 2017 (consultado el 7 de noviembre de 2019).

31 Sobre la competencia del Poder Judicial Local del Estado de Nayarit, véase el artículo 82, fracción III, de la Constitución Política del Estado Libre y Soberano de Nayarit (consultada el 7 de noviembre de 2019).

32 De esta legislación es destacable su tendencia a no reconocer derechos adquiridos como la antigüedad en el empleo, que eventualmente puede tener como resultados la basificación y, desde luego, la seguridad y estabilidad laboral en las relaciones burocráticas; lo que no empata con los Estados sociales y democráticos. 
el Estado de Nayarit, pero que próximamente será sustituido por el Instituto de Justicia Laboral Burocrática del Estado de Nayarit. ${ }^{33}$

Bajo esa lógica, los docentes en activo que resultan ser trabajadores al servicio del Estado en Nayarit, de sentirse vulnerados con relación a su promoción horizontal, podrían invocar para la exigencia de sus derechos la Ley Laboral Burocrática del Estado de Nayarit y, en todo caso, acudir al Tribunal de Conciliación y Arbitraje en el Estado de Nayarit, en tanto se crea el Instituto de Justicia Laboral Burocrática del Estado de Nayarit; enfocando esa exigencia hacia la antigüedad y preferencia que consigna la legislación laboral. Y del mismo modo estarían en posibilidad de invocar los contenidos normativos de la Ley General del Sistema para la Carrera de las Maestras y los Maestros (LGSCMM), según lo disponen sus artículos 103 y 107. Aunque esto no parece ser lo más idóneo, porque la promoción horizontal debe ser vista como un derecho poliédrico y no exclusivo de la materia laboral.

\section{La vía administrativa}

Conviene precisar que la LGSPD, en sus artículos 80, 81, 82 y demás relativos, contemplaba el recurso de revisión para atacar las resoluciones administrativas que derivaran de la aplicación correcta del proceso de evaluación. Mecanismo de defensa que, de una interpretación sistemática de dicho cuerpo normativo, se consideró sólo para los procesos de evaluación que expresamente fueron llevados a cabo, con sus respectivas convocatorias y lineamientos correspondientes, a saber: la evaluación de oposición, la evaluación de desempeño (obligatoria, y sin marco normativo para la promoción horizontal) y la evaluación para las funciones directivas. Sin embargo, no se hablaba expresamente del proceso a través del cual era posible llevar a cabo la promoción horizontal, lo que colocó en estado de indefensión a los docentes en activo para exigir dicho derecho, toda vez que se careció de la regulación respectiva.

Y entonces, de accionarse tal mecanismo no era la vía idónea debido a que los docentes en los casos concretos que no fueron promovidos no se dolían del proceso de evaluación en sí, sino de la actitud omisa por parte de las autoridades educativas, que además dieron trato igual a docentes de nuevo ingreso regidos por una lista de prelación (evaluación de oposición) y a docentes en activo a quienes se les debió de emitir una convocatoria de promoción

$33 \mathrm{Al}$ respecto véase el artículo quinto transitorio de la Ley Laboral Burocrática del Estado de Nayarit, del 31 de mayo de 2019, consultada el 7 de noviembre de 2019. 
horizontal, y en todo caso debieron de haber sido evaluados en desempeño con ese mismo fin y no sólo para su permanencia. Es decir, no había expresamente un medio de impugnación ante irregularidades u omisiones en la promoción horizontal, porque para tales efectos no había la necesidad de un proceso de evaluación, sino que bastaba con reunir los requisitos de ley.

Ahora bien, por su parte la actual Ley General del Sistema para la Carrera de las Maestras y los Maestros, consigna en sus artículos 103, 104 y siguientes, la posibilidad de interponer recurso de reconsideración en contra de las resoluciones administrativas que se pronuncien en los términos de la norma en comento. Precisándose que dicho recurso versará exclusivamente respecto de la aplicación correcta del proceso de selección. En donde, de nueva cuenta no hay espacio para la exigencia de un derecho respecto al cual se reclama una conducta omisa y sistemática de la autoridad educativa, es decir, ante la eventual falta de operatividad de la promoción horizontal.

\section{El juicio de amparo indirecto}

Bajo el panorama previamente expuesto, entendiendo a la promoción horizontal como un derecho poliédrico que impacta o influye en el desenvolvimiento de otros derechos y ante una eventual omisión sistematizada de operativizar tal derecho por parte de la autoridad educativa local; al no haber emitido convocatoria o lineamientos al respecto, y dejar en estado de vulnerabilidad a docentes en activo, violando normas de carácter general, el camino más plausible para hacer frente a dicha violación es el juicio de amparo indirecto, a través del cual la autoridad constitucional determine no sólo la existencia de dicha violación sino además los alcances y efectos de ésta.

Es decir, conviene resaltar que la falta de lineamientos o convocatoria sobre dicha promoción, ${ }^{34}$ muestra una omisión por parte de la autoridad educativa que, aunado al hecho de reunir los requisitos de ley, permiten a un docente en activo el exigir tal derecho en instancias federales, mediante un juicio de amparo indirecto, sin agotar previamente recurso o medio de impugnación ordinario.

34 Conviene precisar que actualmente parece que se están trabajando los correspondientes lineamientos para la promoción horizontal en Nayarit por parte de las autoridades educativas locales a través de un proceso de réplica que viene desde nivel federal y está proyectado para un futuro próximo. Sin embargo, hasta en tanto no suceda eso la problemática subsiste y es una evidente violación a derechos sociales en perjuicio de docentes en activo. 


\section{RETOS Y PERSPECTIVAS}

B ajo el esquema de un Estado constitucional social y democrático de derecho, las autoridades del Estado mexicano están obligadas a desempeñar un papel más activo frente al reconocimiento, promoción y garantía de derechos humanos. Ya no basta sólo con su no intromisión, sino que ahora se requiere de la implementación constante de políticas públicas para hacer asequibles cierto tipo de derechos sociales.

En el supuesto específico, las autoridades educativas deben de reconocer y promover activamente el desarrollo horizontal de docentes en activo para la obtención de horas adicionales. Ello sería coherente con la antigüedad y la preferencia en materia laboral, así como con el principio de progresividad, al tiempo que contribuiría indirectamente a la calidad educativa.

Tanto la Ley General del Servicio Profesional Docente como la Ley General de la Carrera de Maestros y Maestras, reconocieron tal derecho; sin embargo, no es suficiente con su consignación en la norma si a esa promoción horizontal no se le da operatividad a través de convocatorias y lineamientos claros y precisos, que consignen el proceso, los plazos y formas de hacer asequible tal derecho. Se requiere de un sentido de responsabilidad y disponibilidad al respecto por parte de las autoridades competentes.

Las autoridades educativas, de acuerdo con la legislación citada en el párrafo previo, están obligadas a hacer una clara distinción entre docentes en activo y docentes de nuevo ingreso, porque las circunstancias bajo las cuales son evaluados son totalmente distintas. Para recuperar la credibilidad de las evaluaciones docentes, en sus distintas modalidades, sería conveniente considerar la participación de instituciones externas como Ceneval.

Sería loable que la promoción horizontal sea concebida como un derecho poliédrico por su impacto en distintos ámbitos. Se requiere de una interpretación amplia de dicho derecho por parte de las autoridades educativas, es forzosa su operatividad a través de lineamientos y es imperdonable su falta de respeto y garantía como un derecho social por la estructura del propio Estado. 


\section{FUENTES DE CONSULTA}

Carbonell, Miguel y Ferrer Mac-Gregor, Eduardo, Los derechos sociales y su justiciabilidad directa, México, Editorial Flores-UNAM, Instituto de Investigaciones Jurídicas, 2014.

Carbonell, Miguel, Los derechos fundamentales en México, 3a. ed., México, UNAM-Porrúa-CNDH, 2009.

FERRAJOLI, Luigi, "Contra los poderes salvajes del mercado: para un constitucionalismo de derecho privado", trad. de Miguel Carbonell, en CARBONELL, M. et al. (coords.), Estrategias y propuestas para la reforma del Estado, 2a. ed., México, UNAM, Instituto de Investigaciones Jurídicas, 2002.

FERRAJOLI, Luigi, "La esfera de lo indivisible y la división de poderes", Estudios Constitucionales, Santiago de Chile, Centro de Estudios Constitucionales de Chile, Universidad de Talca, año 6, núm. 1, 2008.

Ferrajoli, Luigi, Constitucionalismo más allá del Estado, Madrid, Trotta, 2018.

Ferrajoli, Luigi, Derechos y garantías. La ley del más débil, 4a. ed., Madrid, Trotta, 2004.

FiX-ZAMudio, Héctor y VAlEnCia CARMONA, Salvador, Las reformas en derechos humanos, procesos colectivos y amparo como nuevo paradigma constitucional, México, Porrúa-UNAM, 2015.

GARCÍA RAMírEZ, Sergio y MORALES SÁNCHEZ, Julieta, La reforma constitucional sobre derechos humanos, México, Porrúa-UNAM, 2012.

Gómez Romo de Vivar, Guillermo Rafael y Olivos Fuentes, Monserrat, "La construcción jurisdiccional de los procesos de consulta de las comunidades indígenas y su aproximación al derecho a la información en México", Revista Derecho del Estado, núm. 45, enero-abril de 2020.

GÓmez Romo DE VIVAR, Guillermo Rafael, “Armonía jurídica-institucional: una propuesta para la función gubernamental”, en GÓMEZ ROMO DE VIVAR, Guillermo Rafael et al. (coords.), Democracia, gobierno y participación ciudadana, México, Tiran lo Blanch, 2019.

LASAlle, Ferdinand, ¿Qué es una Constitución?, 2a. ed., trad. de Luis Rutiaga, México, Grupo Editorial Tomo, 2013.

MARTÍNeZ LOBATO, Lilia et al., Reforma educativa y profesores. Percepción sobre los procesos de evaluación, San Luis Potosí, XIV Congreso Nacional de Investigación Educativa, 2017. 
Murillo TORRECILLA, F. Javier (coord.), Evaluación del desempeño y carrera profesional docente. Un estudio comparado entre 50 paises de América y Europa, Chile, ONU-UNESCO-Ministerio de Educación y Ciencia en España, 2007.

PERALTA, Victoria, "El bienestar como fin para la construcción de la calidad en la educación de la primera infancia”, en PERALTA, Victoria y HERNÁNDEZ, Laura (coords.), Antología de experiencias de la educación inicial iberoamericana, Madrid, OEI-Unisef-BBVA, 2012.

SEP-SNTE, Comisión Nacional de Carrera Magisterial, Lineamientos generales de carrera magisterial, México, 1998.

SILVA MEZA, Juan N., "El impacto de la reforma constitucional en materia de derechos humanos en la labor jurisdiccional en México", Anuario de Derecho Constitucional Latinoamericano, Colombia, Konrad Adenauer, año XVIII, 2012.

VALADÉS, Diego, "La protección de los derechos fundamentales frente a particulares", en VON BOGDANDY, Armin et al. (coords.), La justicia constitucional y su internacionalización, México, UNAM, Instituto de Investigaciones Jurídicas, 2010, t. I.

Vergara Moreno, Benito José, "Los sindicatos frente a las reformas estructurales", Revista del Instituto de la Judicatura Federal, México, núm. 46, 2018. 